\title{
Assessment of Knowledge, Attitude and Practice on Initiation of Complementary Feeding Among Under Two Years Children in Fiche Town, North Showa Zone, Ethiopia
}

\author{
Rebik Shukure \\ Department of Nursing, Selale University, Collage of Health Science, Fiche, Oromia, Ethiopia
}

Email address:

rebikshukure@gmail.com

\section{To cite this article:}

Rebik Shukure. Assessment of Knowledge, Attitude and Practice on Timely Initiation of Complementary Feeding Among Under Two Years Children in Fiche Town, North Showa Zone, Ethiopia. International Journal of Biomedical Engineering and Clinical Science.

Vol. 3, No. 6, 2017, pp. 103-109. doi: 10.11648/j.ijbecs.20170306.16

Received: February 4, 2017; Accepted: February 27, 2017; Published: December 14, 2017

\begin{abstract}
Background: - Healthy complementary feeding is critical for the achievement of a healthy growth and development of children. In Ethiopia inappropriate complementary feeding practices, combined with poverty, are major determinants of the high prevalence of malnutrition among young children. Community based a prospective cross- sectional study was conducted from December to January 2015/2016. Almost two-third of the mothers initiated complementary feeding at the sixth month of child's age. Factors like maternal and husband educational level, family size, place of delivery, ANC follow up, and PNC follow up were significantly. Most mothers initiate complementary feedings timely. Maternal literacy, family size and relation of mothers affect timely initiation of complementary feeding. Educating the mothers by mass media and house to house by health extension workers is important to increase timely initiation of complementary feeding.
\end{abstract}

Keywords: Complementary Feeding, Knowledge, Attitude and Practice

\section{Introduction}

As world Health Organization, Complementary feeding is the process starting when breast milk alone is no longer sufficient to meet the nutritional requirements of infants, and therefore other foods and liquids are needed, along with breast milk. The transition from exclusive breast feeding to family food referred to as complementary. [1]

The period from birth to two years of age is the "critical window" for the promotion of optimal growth, health and development of a child, especially since it is during this period that children are particularly vulnerable to growth retardation, micro-nutrient deficiencies, and common childhood illnesses. [2]

Initiating complementary feeds too early or too late can lead to malnutrition. The early introduction of complementary feeding before the age of six months can lead decrease absorption and digestion of breast milk and increased risk of morbidity such as diarrhea, which further contributes to weight loss and malnutrition. Studies show that early introduction of complementary feeding does not result in improved growth velocities or food acceptance. Therefore, the recommended age range of complementary feeding is generally 6-24month [3] but when there is medical condition and families in difficult situations require special attention and practical support in order to optimally feed their young children. These special circumstances include feeding malnourished infants less than 6 months of age, feeding during illnesses, feeding infants born to HIV positive women, and children living in special circumstances, such as orphans and vulnerable children or infants born to adolescent mothers. In these situations, mothers and babies should receive adequate support. [4]

Inappropriate feeding practices are a major cause of the onset of malnutrition in young children. Children who are not breastfed appropriately have a repeated infection, decrease their growth and mental development. And after six month, inappropriate complementary feeding increase the incidence of malnutrition rises sharply during the period from 6 to 18 months of age in most countries, and the deficits acquired at this age are difficult to compensate for later in childhood. [5]

Globally speaking, under nutrition is estimated to cause 3.1 million child deaths annually or $45 \%$ of all deaths. Infant and 
young child feeding is key area to improve child survival and promote healthy growth and development. Malnutrition is directly or indirectly responsible for $60 \%$ of the 10.9 million deaths annually among children less than 5 years old. Inappropriate feeding practices attribute to over two thirds of these deaths, and occur during the period of infancy. Appropriate complementary feeding has the potential to prevent $6 \%$ of all under 5 deaths particularly in developing countries $[6,7,8$, and 9].

The prevalence of complementary feeding from 6-8 months among children in the world was $60 \%$, in Latin America and Caribbean $71 \%$ of children received complementary feeding or soft, semi-solid and solid food from 6-8 months [10].

A study conducted in Ghana 2013 showed that $55 \%$ of the mothers had introduced other foods beside breast-milk within the ages of 3-4 months. However, $37.7 \%$ mothers introduced foods within the 5th and 6th months of their infants' life. Mothers complementary feeding practice were affected by family, friends and health workers in shaping current infant feeding practices. Meanwhile mothers with tertiary schooling were practicing formula feeding more than their counterparts. Mothers' employment status was strongly associated with complementary feeding [11].

Study conducted on Nepal in 2015, showed $77.7 \%$ of the mothers knew that the correct age to start complementary feeding was at 6 months of age. Irrespective of whether the mothers knew the appropriate age to start complementary feeds, in practice, only $50 \%$ of the mothers started complementary feeds at 6 months of age. In this study $40.3 \%$ of the mothers started complementary feeds before the recommended time and $9.7 \%$ delayed it beyond six months of age. [12]

The study conducted in Eastern Ethiopia in 2014 showed that timely initiation of complementary feeding of mothers was low. More than half of them initiated complementary feeding timely. Less than a quarter of the women initiated complementary feeding early between 4-6 months. The main reason given by the mothers for early initiation of complementary feeding was lack of knowledge. Majority of the mothers initiate semi-solid complementary feeding liquid such as porridge and soup prepared from milk products. [13]

\section{Methods and Materials}

\subsection{Study Area and Period}

The study was conducted in Fiche town, north Shewa, Ethiopia from December to January 2/ 2016. Fiche is the administrative center of the north Shewa zone. It is located about $112 \mathrm{~km}$ from Addis Ababa. It has a latitude and longitude of $948^{\prime} \mathrm{N} 3844^{\prime} \mathrm{E}$ and an elevation between 2,738 and 2,782 meters above sea level. Fiche town is divided in to 4 Kebele, and the numbers of households were 8315 .

According to the information we obtained from the administration of fiche town, the basic infrastructures include one public hospital, two health centers, seven private clinics, six private pharmacies, eight kindergartens, twelve primary schools, two secondary schools, one preparatory school, two governmental collages, ten private collages and one university. The total water coverage is greater than $79 \%$.

According to the information we obtained from the fiche town health office bureau, based on the 2010 census the total number of population was about 39910 of whom 20287 were women. Among these women 8315 were in reproductive age. The numbers of mothers who had under 2 years children were 2043. Among them the numbers of mothers who had children between 6-24 months were 1489 .

\subsection{Population}

The Source of population was all mothers with under 2 years children and Study population was the sampled mothers with under 2 year children

\subsection{Study Design Sampling Technique and Sample Size Determination}

A Community based a prospective Cross-sectional study design. The sample size was determined by using a formula for estimating a single population proportion with confidence interval of $95 \%, 5 \%$ marginal error, and $10 \%$ none response rate, a total of 250 mothers were required for the study. The prevalence of timely initiation of complementary feeding in north Ethiopia is $78.9 \%$. A list of sample frame was prepared from each Keble by using a lottery method. Then the study subjects were selected by simple random sampling. The data was collected from each mother in the sample.

\subsection{Data Processing and Analysis}

Data was checked for completeness, consistencies and it was cleaned, coded, entered and analyzed using SPSS for window version 20. Data frequencies and percentage were calculated to all variables that are related to the objectives of the study.

\subsection{Data Quality Control}

Data collection instruments were pretested on $5 \%$ similar mothers who have under two years to check the validity and reliability. We used simple random sampling method. In addition, data collectors adequately trained for one day on the administration and checking of completeness of the questionnaire.

\subsection{Ethical Consideration}

Letter of approval was obtained from the advisor and the department. Then it was submitted to ethical review committee of AAU for ethical review. The permission letter from the ethical review committee was submitted to CBE coordination office of AAU to grant letter or cooperation. The letter of cooperation was given to each of the Keble of Fiche town, Fiche health bureau and administrative office. The respondents were informed about the objective and purpose of the study and verbal consent was obtained from each respondents. They had the rights to refuse or withdraw from the study.

\subsection{Dissemination of the Finding}

The findings of this study will be distributed to health and 
administrative offices of Fiche town. Copy of the research report will be submitted to the department of nursing, AAU, Selale campus. An attempt will be made to publish it on national and international journals.

\section{Result}

\subsection{Socio-demographic Variable of Respondents}

A total of 250 mothers were participated in the study with response rate of $100 \%$. the mean age of mother's was 26.2 years with \pm 7.4 SD years. Regarding the educational status of respondent, most of the mothers $80(32 \%)$ were can not read and write. Majority Of the participant family size, $100(40 \%)$ had 4 to 6 members in their household and 175 (66\%) had one under five child. More than half of the respondent mothers were house wife. Ninety (36\%) of the respondents husbands were government employed and one fourth 64(25.6\%) children were 11-14months age. findings are presented in table

Table 1. Distribution of socio-demographic variables of respondents in Fiche town.

\begin{tabular}{|c|c|c|}
\hline characteristics & frequency & percent \\
\hline \multicolumn{3}{|c|}{ Age of mother in the (years) } \\
\hline $15-24$ & 61 & 24.4 \\
\hline $25-34$ & 113 & 45.2 \\
\hline $35-49$ & 76 & 30.4 \\
\hline Total & 250 & 100 \\
\hline \multicolumn{3}{|l|}{ Age of child(in months) } \\
\hline $1-5$ & 40 & 16 \\
\hline $6-10$ & 60 & 24 \\
\hline $11-14$ & 64 & 25.6 \\
\hline $15-19$ & 48 & 19.2 \\
\hline $20-24$ & 38 & 15.2 \\
\hline total & 250 & 100 \\
\hline \multicolumn{3}{|c|}{ Mother current occupational status } \\
\hline House wife & 105 & 42 \\
\hline Student & 15 & 6 \\
\hline Government employed & 35 & 14 \\
\hline Private business & 60 & 24 \\
\hline Farmer & 35 & 14 \\
\hline total & 250 & 100 \\
\hline \multicolumn{3}{|l|}{ Mother educational status } \\
\hline Illiterate & 80 & 32 \\
\hline Can read and write & 40 & 16 \\
\hline Grade $1-4$ & 30 & 12 \\
\hline Grade 5-8 & 35 & 14 \\
\hline Grade 9-12 & 30 & 12 \\
\hline College diploma & 25 & 10 \\
\hline University degree & 10 & 4 \\
\hline total & 250 & 100 \\
\hline \multicolumn{3}{|l|}{ Family size } \\
\hline $1-3$ & 60 & 24 \\
\hline $4-6$ & 100 & 40 \\
\hline $7-10$ & 90 & 36 \\
\hline total & 250 & 100 \\
\hline \multicolumn{3}{|c|}{ Monthly income of the house hold } \\
\hline$<500$ & 58 & 23.2 \\
\hline $500-1000$ & 122 & 48.8 \\
\hline $1000-1500$ & 31 & 12.4 \\
\hline $1500-2000$ & 26 & 10.4 \\
\hline$>2000$ & 14 & 5.6 \\
\hline total & 250 & 100 \\
\hline
\end{tabular}

\subsection{Mother Knowledge on Initiation of Complementary Feeding in Fiche Town}

Among the total respondents of 250, 160(64\%) were heard about complementary feeding. Out of the mothers who form heard about complementary feeding, one hundred $(62.5 \%)$ of women obtained the information from they went to health institution and half of them $86(52.5 \%)$ got the information from health extension workers. From this $30(18.75 \%)$ mother were get the information weekly, others $30(18.75 \%)$ and $100(62.5 \%)$ were get the information monthly and when they go to health institution respectively.

Among the 250 mothers, most of the respondents (61.2\%) answered the proper time for starting complementary feeding at six months, others, immediately after birth, 1-3 months, 4-6 months, -12 months, above 12 months are $18(7.2 \%)$, $13(5.2 \%), 27(10.8 \%) .21(8.4 \%)$ and $18(7.2 \%)$ respectively.

Table 2. Mother Knowledgeon Initiation of Complementary Feedingin Fiche Town.

\begin{tabular}{|c|c|c|}
\hline Characteristics & frequency & percent \\
\hline \multicolumn{3}{|l|}{ Heard about complementary feeding } \\
\hline Yes & 160 & $64 \%$ \\
\hline no & 95 & $36 \%$ \\
\hline \multicolumn{3}{|l|}{ Frequency of obtaining information } \\
\hline Weekly & 30 & 18.75 \\
\hline Monthly & 30 & 18.75 \\
\hline When I visit health institution & 100 & 62.5 \\
\hline $\begin{array}{l}\text { Total } \\
\text { information source of Complementary feeding }\end{array}$ & 160 & 100 \\
\hline Radio & 5 & 3.1 \\
\hline Television & 15 & 9.4 \\
\hline Health extension workers & 86 & 52.5 \\
\hline Health institution & 54 & 33.75 \\
\hline total & 160 & 100 \\
\hline \multicolumn{3}{|l|}{ Proper time initiate $\mathrm{CF}$} \\
\hline Immediately & 18 & 7.2 \\
\hline 1-3 months & 13 & 5.2 \\
\hline 4-6 months & 27 & 10.8 \\
\hline At 6 month & 153 & 61.2 \\
\hline 7-12 months & 21 & 8.4 \\
\hline After 1 year & 18 & 7.2 \\
\hline total & 250 & 100 \\
\hline \multicolumn{3}{|l|}{ Best preparation of food at the beginning time } \\
\hline Soup & 115 & 46 \\
\hline Semi solid & 100 & 40 \\
\hline Solid & 35 & 14 \\
\hline total & 250 & 100 \\
\hline
\end{tabular}

\subsection{Attitude of Mothers on Initiation of Complementary Feeding in Fiche Town}

Half of the women reported complementary feeding is important. 76(30.4\%) reported moderately important and $43(17.2 \%)$ of mother reported complementary feeding was not important for child development and growth.

Half of women113 (53.3\%) were think early introduction of complementary feeding likely caused child illness, however $33(13.2 \%)$ of women reported unlikely cause complementary feeding. Three forth of women agreed on exclusive breast milk are not enough for the child before six month and antenatal visit is used to get information about 
complementary feeding.

Table 3. Mothers attitude on initiation of complementary feeding in Fiche town.

\begin{tabular}{lll}
\hline Characteristics & frequency & percent \\
\hline Importance of CF for child development & & \\
Moderately important & 76 & 30.4 \\
Important & 131 & 52.4 \\
Not important & 43 & 17.2 \\
Total & 250 & 100 \\
likely of early introduction of CF can expose child to illness & \\
Very High Likely & 15 & 6 \\
High likely & 89 & 35.6 \\
Likely & 113 & 53.2 \\
Unlikely & 33 & 13.2 \\
total & 250 & 100 \\
exclusive breast milk is enough for the child before six month & \\
Strongly agree & 78 & 31.2 \\
Agree & 122 & 48.8 \\
Not agree & 50 & 20 \\
total & 250 & 100 \\
Importance high level of maternal education for initiation of CF & \\
Strongly agree & 97 & 38.8 \\
Agree & 150 & 60 \\
Not agree & 3 & 2.2 \\
& 250 & 100 \\
\hline & & \\
& & \\
& & \\
& &
\end{tabular}

\subsection{Practice of Mothers on Initiation of Complementary Feeding in Fiche Town}

Among the total respondents, 210(84) of women were initiate complementary feeding. 129(61.5\%) of mothers initiate complementary feeding timely. forty nine $(23.3 \%)$ of mothers were early initiate complementary feeding, and late initiation of complementary feeding was $32(15.2 \%)$. The main reason for early initiation of complementary feeding was due to inadequate breast milk production $15(37.5 \%)$, and lack of knowledge 11(27.5\%),

All most all mothers were give breast milk before starting complementary feeding $247(98.8 \%)$, from this $147(69.8 \%)$ of the women feed their child four times and above per day.. Among them 106(42\%) of mother were changed breast feeding frequency after initiation of complementary feeding. Sixty one percent of mothers were prepared complementary feeding by three type food. However $85(40.5 \%)$ of mothers were usually use milk and milk product to prepare complementary food.

About half of the mothers were use bottle feeding, $80(38.1 \%)$ were use cup and spoon and 19(9\%) use both bottle feeding and cup and spoon.

One hundred thirty four $(63.1 \%)$ of mothers feed their children three times per day, 57(27.1\%) feed two times per day. however $19(9 \%)$ feed their children one times per day. Half of the mothers were feed their children separately, but $12.4 \%$ of mothers were feed their child with care giver. Twothird of husbands supported by economical but 23 (11\%) had no any support.
Table 4. Practice of mothers on initiation of complementary feeding in Fiche town.

\begin{tabular}{|c|c|c|}
\hline Characteristics & frequency & percent \\
\hline \multicolumn{3}{|l|}{ providing complementary feeding } \\
\hline Yes & 210 & 84 \\
\hline No & 40 & 16 \\
\hline Total & 250 & 100 \\
\hline \multicolumn{3}{|l|}{ Reason not start } \\
\hline I do not know when to start additional food & 11 & 27.5 \\
\hline Not comfortable with work & 6 & 15 \\
\hline The child does not want & 2 & 5 \\
\hline the child does not get enough milk from mother & 15 & 37.5 \\
\hline child age is below appropriate time to start $\mathrm{CF}$ & 6 & 15 \\
\hline total & 40 & 100 \\
\hline \multicolumn{3}{|l|}{ type of food offered frequently } \\
\hline Milk & 85 & 40.5 \\
\hline Formula & 14 & 6.7 \\
\hline Cereal & 46 & 21.9 \\
\hline Porridge[atmit] & 65 & 31 \\
\hline Total & 210 & 100 \\
\hline \multicolumn{3}{|l|}{ type of feeding utensils used to feed } \\
\hline bottle & 111 & 52.9 \\
\hline Cup \& spoon & 80 & 38.1 \\
\hline Both & 19 & 9 \\
\hline total & 210 & 100 \\
\hline \multicolumn{3}{|l|}{ role of the husband } \\
\hline Tell the advantage of complementary feeding & 23 & 11 \\
\hline Economical support & 154 & 73.3 \\
\hline Involve in preparing food and feeding the child & 10 & 4.8 \\
\hline No any support & 23 & 11 \\
\hline Total & 210 & 100 \\
\hline
\end{tabular}

\subsection{Health Care Related Characteristics of Respondents in Fiche Town}

Among the study participant mothers, $152(60.8 \%)$ of them reported that they had history of antenatal follow up. from the mothers who had history of antenatal follow up, 109(71.7\%) of the mother for reason for regular checkup. two third of them $73(48 \%)$ of women had three time antenatal care during their pregnancy. Half of mothers $(56 \%)$ gave birth at home. forty two percent (102) had postnatal visit.

Table 5. Health care related factors of timely initiation of complementary feeding.

\begin{tabular}{lll}
\hline characteristics & frequency & percent \\
\hline Antenatal follow up & & \\
Yes & 152 & 60.8 \\
No & 98 & 39.2 \\
Total & 250 & 100 \\
Reason for antenatal follow up & & \\
Once & 12 & 6 \\
Twice & 15 & 9.9 \\
Three time & 73 & 48 \\
Four time & 52 & 34.2 \\
total & 152 & 100 \\
Delivery service & & \\
Home & 140 & 56 \\
Health center & 65 & 26 \\
Clinic & 20 & 8 \\
Hospital & 25 & 10 \\
total & 250 & 100 \\
Postnatal visit & & \\
Yes & 105 & 42 \\
No & 145 & 58 \\
total & 250 & 100 \\
\hline
\end{tabular}




\subsection{Factor Affecting Initiation of Complementary Feeding}

After applying binomial logistic expression age of mothers $(\mathrm{p}=0.05)$, relation of mother to the house hold $(\mathrm{p}=0.012)$, maternal education $=(0.00)$, husband education $(0.00)$, maternal current occupation, $(\mathrm{p}=0.067)$, family size $(0.01)$, ANC $(p=0.00)$, reason for antenatal visit $(p=0.01)$, time of visit $\mathrm{p}=(0.09)$, place of delivery $\mathrm{p}=(0.00)$ and $\mathrm{PNC}(\mathrm{p}-$ 0.00 )are a significant association with timely initiation of complementary feeding Illiterate (5.78 (1.38-24.32) women were six time less likely initiate complementary feeding than women who had diploma), family size 1-3 were two times more likely initiate complementary feeding than their counter part $(\mathrm{OR}=1.79$ (1.27-2.73), mothers had one child $(\mathrm{OR}=2.99,95 \% \mathrm{CI}(1.79$ (1.27-2.73)), mothers who were house wife (OR 2.05, 95\% CI(0.67-6.00) as educational status of husband increase the timely initiation of mothers improve, Mothers who get information during antenatal visit three times more likely initiate complementary feeding timely than mothers who did not get information during of antenatal visit $(\mathrm{OR}=2.795 \% \mathrm{CI}(1.34-5.44)$. Mothers who had history of post natal care visit more likely initiate complementary feeding timely than mothers who had not history of postnatal visit.

Table 6. Binary logistic regressions of associated factors with complementary feeding practice of mothers in Fiche town.

\begin{tabular}{|c|c|c|c|c|}
\hline \multirow[t]{2}{*}{ variable } & \multicolumn{2}{|c|}{ Complementary feeding initiation } & \multirow[t]{2}{*}{ OR 95\% CI } & \multirow[t]{2}{*}{$P$ value } \\
\hline & TIMELY & NOT TIMELY & & \\
\hline Age of mother & & & & 0.05 \\
\hline $15-24$ & $22(36.1 \%)$ & $39(63.9 \%)$ & $0.61(0.43-0.86)$ & \\
\hline $25-34$ & $59(52.2 \%)$ & $54(57.8 \%)$ & - & \\
\hline $35-49$ & $40(60.5 \%)$ & $30(39.5 \%)$ & - & \\
\hline Relation of mother & & & & 0.012 \\
\hline House wife & $91(47.4 \%)$ & $101(52.6 \%)$ & 2.93(1.38-6.19) & \\
\hline Daughter & $7(38.9 \%)$ & $11(61.1 \%)$ & $4.14(1.28-13.4)$ & \\
\hline Head of house hold & $29(72.5 \%)$ & $11(27.5 \%)$ & - & \\
\hline Mother educational status & & & & 0.00 \\
\hline Illiterate & $34(42.0 \%)$ & $47(58 \%)$ & $5.78(1.38-24.32)$ & \\
\hline Can read and write & $23(59 \%)$ & $16(41 \%)$ & $7.00(1.52-32.33)$ & \\
\hline Grade 1-4 & $13(43.3 \%)$ & $17(56.6 \%)$ & $3.05(0.66-14.13)$ & \\
\hline Grade 5-8 & $16(45.7 \%)$ & $19(54.3 \%)$ & $0.39(008-2,02)$ & \\
\hline Grade 9-12 & $19(65.6 \%)$ & $10(34.4 \%$ & $0.71(0.14-3,5)$ & \\
\hline College diploma & $21(80.8 \%)$ & $5(79.2 \%)$ & $0.44(0.08-2.5)$ & \\
\hline University degree & $6(60 \%)$ & $4(40 \%)$ & - & \\
\hline Family size & & & & 0.001 \\
\hline $1-3$ & $41(69.5 \%)$ & $18(20.5 \%)$ & $1.79(1.27-2.73)$ & \\
\hline 4-6 & $49(49.5 \%)$ & $50(50.5 \%)$ & - & \\
\hline $7-10$ & $37(40.2 \%)$ & $55(59.8 \%)$ & - & \\
\hline Mother current occupational status & & & & 0.067 \\
\hline Government employed & $16(45.7 \%)$ & $19(54.3 \%)$ & $0.33(0.14-0.76)$ & \\
\hline Private business & $23(38.3 \%)$ & $37(61.7 \%)$ & $1.24(0.65-2.33)$ & \\
\hline Farmer & $14(56 \%)$ & $11(44 \%)$ & $1(0.47-2.15)$ & \\
\hline Student & $7(63.8)$ & $8(36.2 \%)$ & $1(0.37-3.19)$ & \\
\hline House wife & $67(46.7 \%)$ & $38(53.3 \%)$ & - & \\
\hline Antenatal care & & & & 0.00 \\
\hline Attend ANC & $92(60.5)$ & $60(39.5 \%)$ & $0.36(0.21-0.61)$ & \\
\hline Not attend ANC & $35(35.7 \%)$ & $63(64.3 \%)$ & - & \\
\hline Time of visit & & & & 0.09 \\
\hline One time & $9(75 \%)$ & $3(25 \%)$ & $3.063(1.51-6.1)$ & \\
\hline Two time & $9(60 \%)$ & $6(40 \%)$ & $.630(1.51-$ & \\
\hline Three time & $38(51.4 \%)$ & $36(48.6 \%)$ & $2.6) 1.259(0.34 .1)$ & \\
\hline Four time & $34(65.4 \%)$ & $18(34.6 \%)$ & $1.789(0.863 .7)$ & \\
\hline Place of delivery & & & & 0.000 \\
\hline Home & $41(29.1 \%)$ & $100(70.9 \%)$ & $9.76(3.43-27.75)$ & \\
\hline Health center & $55(85.9 \%)$ & $9(14.1 \%)$ & $0.66(0.2-$ & \\
\hline Clinic & $11(55 \%)$ & $9(45 \%)$ & $2.19) 3.27(0.8812 .22)$ & \\
\hline hospital & $20(80 \%)$ & $5(20 \%)$ & - & \\
\hline Postnatal care & & & & 0.00 \\
\hline Had PNC & $72(68.6 \%)$ & $33(31.4 \%)$ & $0.28(0.17-0.47)$ & \\
\hline NOT PNC & $55(37.9 \%)$ & $90(62.1 \%)$ & & \\
\hline
\end{tabular}

\section{Discussion}

Findings from this study showed that the prevalence of timely initiation of complementary feeding among mothers with under 2 years children was $61.5 \%$. Twenty three percent of mothers were early initiate complementary feeding, but a study in Jimma [15] showed that $42.9 \%$ of the mothers introduced complementary food before 6 months, this is Relatively lower proportion of early initiation of 
complementary feeding may be explained by the fact that the presence of continuous effort towards improving children nutritional status in Fiche town through community participation and nutritional education given by health extension workers. The main reason for early initiation of complementary feeding was due to maternal perception of inadequate breast milk production for child development $37.5 \%$ and lack of knowledge $27.5 \%$. late initiation of complementary feeding was 32(15.2\%). Both early and late initiation account $32(15.2 \%)$. This is lower than Chad $68 \%$, Senegal $69 \%$, niger $78 \%$ and Tigrai [16]. these maybe due to knowledge and some cultural practice. But it is greater than from the study conducted in Nirobi, Kenya (10\%), findings

A higher maternal educational level, high school and above $\mathrm{OR}=1.5,95 \% \mathrm{CI}(0.30-0.70)$ was noted to increase timely initiation of complementary feeding; similar findings were observed by other studies in Ghana [11], Hrara [17] and Tigrai [16] This can be that high level of maternal education increase mothers' awareness and appreciation of the demands and benefits of introducing complementary feeding timely, and empowers them to resist external interferences and pressures on traditional practice and misconception.

In this study nearly two third $158(60.1 \%)$ of mothers had history of ante natal care visit during their pregnancy period. This is higher than a study in Uganda show that only $47 \%$ of women receive antenatal care coverage. This may be due the low overall antenatal care coverage of in the country and low awareness about advantage of ANC [18]

House-wife mothers were more likely to initiation of complementary feeding timely which was in line with finding in other place [13]. This can be because the housewives usually stay at home have chance to attend their child and give breast feeding frequently. But Mothers who work as daily workers, farmers, merchant and Government employed were more likely not initiate complementary feeding as compared to House wife it is supported with others research jimma [16], Harer and Gobe district [19]. This may associated with decrease breast feeding practice to feed their child when go to work purpose, in addition they believe the child is exposed with hunger and water thrust due to lack of time to breast feed frequently. So that they start to initiate early feeding of their child solid and semi-solid food; but House wife mothers are more likely start complementary feeding timely since they stay in home with their child and have sufficient time for frequent breast feeding.

Unlike the study in northern Ethiopia Households with family size of 1-3 were three times more likely to initiate complementary feeding timely than Households with family size greater than or equal [16], this could be due to relatively high birth interval in the household that leads good economic situation, as result the mother complementary initiate feeding timely.

The women who had history of antenatal care visit during pregnancy period and post natal visit initiate complementary feeding timely. A study in Ghana, Harar, Tigrai found out that timely initiation of complementary feeding is become higher with antenatal and Post natal, maternal education, antenatal care and Post natal care $[17,16]$. Mothers who have No post natal visit in Health institution were start early complementary feeding as compared to mothers who have follow up. These finding is supported by study conducted by South West Ethiopia [20]. This is explained Mothers who get Health education and advice on complementary feeding during Post natal visit has great effect $t$ on the timely initiation of complementary feeding. In this study more than two third 139 (69.5\%) of mothers had history of ante natal care visit during their pregnancy period from which the majority (59.0\%) have had more than three times. This is higher than study in Uganda that only $47 \%$ of women receive antenatal care coverage [18]. This may be due the low overall antenatal care coverage of in the country.

\section{Conclusion}

Most mothers initiate complementary feedings timely. Maternal literacy, family size and relation of mothers affect timely initiation of complementary feeding. Current occupation of mothers and husband, place of delivery, maternal ANC and PNC follow up contribute significantly to timely initiation of complementary feedings.

\section{Limitation and Strength of the Study}

\subsection{Limitation}

There was Recall-bias during interview of mothers. In measuring Feed consistency \& food amount that offered was difficulty in Consideration. There were a bias in knowledge $\&$ practice of complementary feeding practice.

\subsection{Strength of the Study}

The study used primary data and Community based cross sectional study was conducted.

\section{References}

[1] WHO. Complementary feeding, e-library of evidence 3 of nutrition actions, March 4, 2016.

[2] Peletier DL. frongillo EA, Schroeder DG and Habicht JP.1995. the effect of malnutrition on child mortality in developing countries. Bull. World Health Organ. 73 (4); 443-8.

[3] Gareth J, Richard WS, Robert EB, Zulfiqar AB, Saul SM; How many child deaths can we prevent this year? Lancet 2003, 362 (9377); 65-71.

[4] Infant and Young Child Feeding Strategy for Puntland20122016 Ministry of Health Garowe- Punt land Produced with support from UNICEF

[5] UNICEF, the importance of appropriate complementary feeding, www.unicef.org/nutrition, 2013, 15-32.

[6] Mekbib E, Shumey A, Ferede S, Haile F: Magnitude and Factors Associated with Appropriate Complementary Feeding among Mothers Having Children 6-23 Months-of-Age in Northern Ethiopia; A Community-Based Cross-Sectional Study. Journal of Food and Nutrition Sciences 2014, 2 (2): 36-42. 
[7] Saleh F, Ara F, Hoque MA, Alam MS: Complementary feeding Practices among Mothers in Slected Slums of Dhaka city: A Descriptive Study. J Health PopulNutr 2014, 32 (1): 96.

[8] Breastfeeding: the lancet

(www.thelance.com/series/breastfeeding) volume 387, issue, $2015,10017,475-490$

[9] Lutter C: Meeting the challenges to improve complementary feeding. Standard Committee on Nutrition News 2003; 27: 4-9.

[10] Senarath U et al. Determinants of inappropriate complementary feeding practices in young children in Sri Lanka: secondary data analysis of Demographic and Health Survey 2006-2007.

[11] Solomon Sika-Bright. Socio-cultural factors influencing infant feeding practices of mothers attending welfare clinic in Cape Coast. Department of Sociology and Anthropology University of Cape Coast, Ghana. January 2010 http://www.ifranigeria.org/IMG/pdf/Sika.pdf. Accessed 7thApril 2014. PubMed | Google Scholar].

[12] Sahisnuta Basnet, Brijesh Sathian, Kalpana Malla, and Deepak Prasad Koirala, "Reasons for Early or Late Initiation of Complementary Feeding: A Study in Pokhara." American Journal of Public Health Research, vol. 3, no. 4A (2015): 69-75. doi: 10.12691/ajphr-3-4A-15.
[13] Agumasie Semahegn, \&, Gezahegn Tesfaye, Alemayehu Bogale Complementary feeding practice of mothers and associated factors in HiwotFana Specialized Hospital, Eastern Ethiopia. The Pan African Medical Journal. 2014; 18: 143.

[14] Jimma Tamiru D, Aragu D, Belachew T. Survey on the introduction of Complementary foods to infants within the first 6 Months and associated factors in rural communities of Jimma. International Journal of Nutrition and Food Sciences. 2013; 2 (2): 77-84. PubMed | Google Scholar.

[15] . [Assessment of knowledge, attitude and practice on timely initiation of healthy complementary feeding among children aged from 6- 24 months in Naeder Adet district, central zone, Tigray, Ethiopia January 2014.

[16] Uganda; Statistics, UNICEF Retrieved 20 February 2012.

[17] Khanal et al. Determinants of complementary feeding practices among Nepalese children aged 6-23 months. BMC Pediatrics.2013; 13:131. PubMed | Google Scholar.

[18] Agedew E, Demissie M, Misker D, Haftu D (2014) Early Initiation of Complementary Feeding and Associated Factors among 6 Months to 2 Years Young Children, in Kamba Woreda, South West Ethiopia: A Community -Based Cross Sectional Study. J Nutr Food Sci 4: 314. doi: 10.4172/21559600.1000314 . 